\title{
The Pleasures and Pitfalls of Teaching Human Evolution in the Museum
}

\author{
Monique Scott
}

Published online: 21 August 2010

(C) Springer Science+Business Media, LLC 2010

\begin{abstract}
As natural history museums are increasingly challenged to represent the complexities of human evolution, new innovations are required to create dynamic, dialogic experiences between museum scientists and museum audiences. After the opening of the Spitzer Hall of Human Origins in 2006, I had the opportunity to take my academic experience in physical anthropology to public education in the Sackler Educational Laboratory for Comparative Genomics and Human Origins. In the lab, I was able to intervene in museum visitors' preconceptions of human evolution in a novel, informal educational setting.
\end{abstract}

Keywords Anthropology · Human evolution · Museum studies $\cdot$ Informal learning $\cdot$ Dioramas

\section{Introduction}

In its "Fashion and Style" section, the Sunday New York Times recently featured an article entitled "The New Age Caveman and the City," which informed readers of "a small New York subculture whose members seek good health through selective return to their Paleolithic ancestors (January 10th New York Times)." Or as one member and some of his friends describe themselves, they are "cavemen." More "authentic" proponents engage in exercise rituals such as sprinting and jumping, playing catch with stones, fasting and feasting, blood-letting, and scooting around the underbrush on all fours, ironically enough. Some have proven their fitness by running across the Brooklyn Bridge bare-chested

M. Scott $(\bowtie)$

American Museum of Natural History,

New York, USA

e-mail: mscott@amnh.org on a frigid night. One dogmatic proponent prefers to describe himself as "a pre-Promethean sort of caveman. Much of his nourishment comes from grass-fed beef, which he eats raw. In a bow to the times, he sometimes uses a fork." Not surprisingly, selected members of the tribe were photographed in front of a diorama at the American Museum of Natural History (AMNH), a diorama featuring reconstructions of modern humans from the Ukraine at 40,000 years ago in the Hall of Human Origins.

Fortunately or unfortunately, we do not live in the Paleolithic Age. Rather, we live in an educationally challenged age where fanciful images of "cavemen" have become canonized as commonsense, if these urban "primitives" are any indication. Visitors to the AMNH come equipped with a weighty set of images drawn from popular culture, derived from romanticized Clan of the Cave Bear tales, Geico Caveman commercials, 10,000 BC, Year One, and Land of the Lost films (as for the latter, a majority of museum visitors I have surveyed were not certain whether dinosaurs and humans co-existed; Scott 2007). Visitors occupy the nexus between the evolutionary folklore generated outside the museum and that which has been generated within it. Facing this constellation of hyperkinetic evolutionary information, museum visitors must negotiate the rocky terrain between evolutionary artistry and the rather esoteric world of evolutionary evidence. For many scientists, popular culture representations of human evolution may seem fanciful and irrelevant to our disciplinethat is, to the real science that happens in museums and other research institutions. But they also represent complex sources of information that visitors bring with them to the natural history museum, as well as the doctor's office, the dinner table, and the voting booth.

Through my work as both a physical anthropology doctoral student at Yale University and as a museum educator at the 
AMNH, I have found that visitors approach the topic of human evolution saturated with a lifetime of preconceptions about human evolution and human prehistory, whether that lifetime is ten or one hundred years. As an anthropology educator, part of my work requires me to mediate between the preconceptions that visitors bring with them to the topic of human evolution and the information that the museum delivers to them through exhibitions and programs. This was something my previous academic work in physical anthropology prepared me to do in theory but not in practice. In this article, I'd like to share with you wisdoms from two journeys - the doctoral and post-doctoral work I conducted researching museum visitor perceptions of human evolution (1996-2004, 2004-2006) and how that has informed the work I've done educating extant hominids visiting the museum about human evolution (from 2006-present).

\section{Part 1: The Academic Encounter}

Arriving at the AMNH as an evolutionary anthropologist, I naively believed that my academic work in physical anthropology, along with the years I spent probing visitor perceptions and misconceptions of human evolution, would guide my way. I had spent years investigating visitor perceptions and misconceptions about human evolution; I had published a book that sought to answer a simple question: "How do museum visitors perceive human evolution exhibitions?" (Scott 2007).

This research interest had itself begun years earlier with another simple question, which I overheard as I eavesdropped on museum visitors. While working as a genetics intern in the AMNH in the 1990s, I overheard a provocative conversation between a mother and her young child. Standing in front of a Homo erectus diorama (now recognized as Homo ergaster) in Africa, which depicts a couple carving raw meat and warding off imposing scavengers on the savanna, the child asked his mother, “Mom, why don't we look like that anymore?" His mother paused a moment before answering succinctly, and surprisingly, "Because we left Africa." This dubious rationale inspired in me a long chain of questions: What exactly happens when visitors encounter such provocative representations of human origins in museums? How do they make sense of them and integrate them into their identities? What set of other conceptual toolswhether popular cultural, intellectual, religious, racial, or political - do visitors bring with them to exhibitions, and how do these tools interact with what is being given to them? And more specifically, how does the trope of "leaving Africa" come to represent a condition or catalyst for evolutionary progress?

After distilling these questions down into a manageable research question, I investigated a variety of human evolutionary exhibition media and reconstructive images. In the process, I also probed, through quantitative and qualitative methods, the diverse ways museum visitors envision their evolutionary origins. I studied museum visitor perceptions in four historic and world-class natural history museums: the Natural History Museum (London), the Horniman Museum (London), the National Museums of Kenya (Nairobi), and the American Museum of Natural History (New York City). Based on this cross-section, I attempted to get at diverse and international perspectives of evolutionary heritage, as well as looking pointedly at perceptions of the "Out of Africa" trope for some of those people actually living "within" Africa.

After collecting questionnaires from nearly 500 visitors internationally and holding in-depth interviews with a selected number of visitors at each institution, I found that teleological or progress-driven concepts of evolution are still used as a crutch by visitors navigating evolutionary information. Even scientifically astute visitors often misunderstand the scale of human evolutionary time and the nature of evolutionary processes; they often find it more satisfying-indeed, need to imagine a progress-driven Africa-to-Europe evolutionary plan, a Victorian progress motif that fixes Africa in static evolutionary prehistory. My work contended that this conceptual rationale remains fundamental to how diverse museum visitors come to understand their African evolutionary heritage, even for many visitors of African descent. Furthermore, it was clear that audiences bring powerful outside images with them to the museum. Visitors at all four museums used similar external frameworks to understand human evolution, images derived more from popular culture than from formal education. At all four museums, at least ninety percent of respondents stated that they'd had previous exposure to information on human evolution, either through school or, more importantly, through such popular media as television, books, magazines, and films.

As we know, museum audiences are more than just the audiences of museums. These audiences participate in wider cultures and subcultures, institutions and practices. So the readings they produce are always "intertextual" and "interdiscursive," symbolic dialogues between the museum visitor, the museum exhibit, and other related media. I found that a handful of media, in particular, impact dramatically the ways a large number of people crossculturally and internationally understand human evolution and Africa. Visitors share common cultural referents and use similar language when discussing their origins; they rely upon a set of familiar icons, such as the Planet of the Apes films, Clan of the Cavebear books, and National Geographic programming. And again and again, visitors reach beyond the museum to television or other visual media when responding to questions. For example, one visitor 
revealed some of his own preconceived assumptions when answering the question, "Do you think of African 'ape-men' as ancestors?" (with me choosing to intentionally use the loaded term "ape-men"). He responded, "You know, one of these programs that I was watching said that there was a tribe in Africa that still lives, how we would call, primitively. They reckon that more or less every single human in this world is related to this tribe. They're saying that Europeans and everyone, there is a common link with this tribe of people who have, you know, obviously not really gone anywhere." Here, television, rather than the museum exhibit he'd just experienced, is invoked to respond to a question about human origins. This visitor's response was uncannily similar to one I heard nearly a decade later while working at the AMNH and passing in front of a diorama in the museum's "Hall of African Peoples." A visitor said, "This is actually how they still live. I've seen it on the television." This is far from an unusual response. Television programs, then, validate the museum (in this instance a diorama from the 1960s) - reinforcing a conditioned nostalgia for a simplified version of a complex people.

Certainly, the same can be said of the image of the Neanderthal "caveman," which relies much on the collective museum visitor imagination —one that has been under construction for the past one hundred years, taking shape on canvas, in the newspaper, on the television and film, or in the museum exhibition. The Neanderthal has always been the quintessential caveman, even as images of Neanderthals have fluctuated in tandem with theories about their phylogenetic proximity to modern humans (Moser 1992, 1996a, 1996b, 1998; Moser and Gamble 1997; Trinkaus and Shipman 1993). By far, the image of the Neanderthal is the most common representative of prehistoric man. Its suite of characteristics - white skin, disheveled hair, stooped posture, vacant expression (the classic characteristics developed by artists such as Zdenek Burian, see Fig. 1)-sells and transports efficiently as an icon.

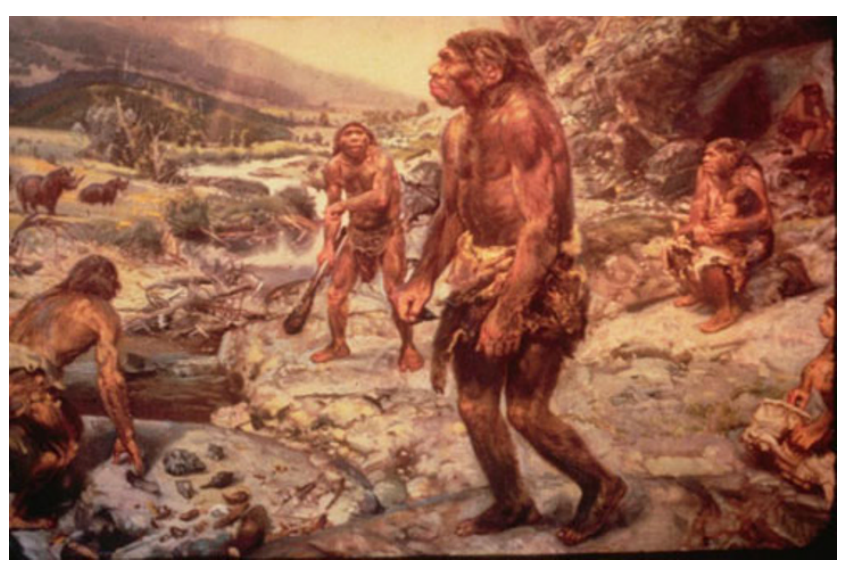

Fig. 1 Classic Neanderthal image, "A Neanderthal Encampment" (Augusta, 1960, Plate 8) illustrated by Zdenek Burian
Many images of the Neanderthal are often juxtaposed comically against the modern European as his brutish prehistoric ancestor. As comic relief, the Neanderthal provides the best mirror for anxieties and fascinations about prehistoric humanity.

The popular 1949 film On the Town devotes a showstealing musical number to the human adoration of cavemen at the AMNH. In this scene, a female anthropologist, smitten with cavemen, sings a song entitled "Prehistoric Man" with a group of dancing sailors. According to Hollywood's construction of the museum's prehistoric and ethnographic galleries, dinosaur skeletons mingle with a hunched Pithecanthropus erectus model (bearing an uncanny resemblance to one of the leading men), and these mix with the usual array of African, Native American, and South East Asian artifacts (drums and masks, canoes and headdresses, totem poles and grass skirts). This cinematic construction highlights the spectacular impact that the AMNH caveman dioramas have had on public perceptions of anthropology and the museum. It also highlights the endless allure of the "caveman," the Western epitome of prehistoric life.

Sixty years after the opening of the Hall of the Age of Man (Henry Fairfield Osborn's first human evolution exhibition at the museum), the AMNH's Hall of Human Biology and Evolution, curated by Ian Tattersall, opened in 1993. The Hall of Human Biology and Evolution was the focus of my visitor studies and was not a disappointment to diorama enthusiasts. The Hall's artistic reconstructions dominate visitor experiences in the exhibition, revealing how its dramatic caveman models often overpower the exhibition of human evolution. The exhibition is punctuated most significantly by its grand dioramas that encapsulate, in four steps, the symbols of humanity: (1) a pairbonded male and female standing upright in the first Australopithecus afarensis diorama, walking along in the volcanic ash (presumably to create the iconic Laetoli footprints); (2) a male and female of the African savanna scavenging for meat in the Homo erectus diorama, with a hyena and vultures menacing on the periphery; (3) a toolmaking family in the Neanderthal diorama, with a man standing sharpening a tool, a woman sitting tanning a hide, and, uniquely, an elder female advising the woman in her work; and, lastly, (4) representatives of modern humanity, a Homo sapiens family from what is now Ukraine.

About the AMNH human evolution dioramas, one interviewee commented to me, "It's just weird the things they have them doing in that one $H$. erectus diorama 'cause it's like, 'oh my god!' These are humans and that's what they did? Whereas here [the Neanderthal diorama] it's like, you kinda know about that stuff, like you see it sometimes, like, in movies or whatever, educational movies. But stuff like that $[H$. erectus] you don't really see." 
Again and again, visitors communicated to me that they identified most with the diorama of the Neanderthal because its constellation of behaviors seemed most familiar. And in fact, as Stephanie Moser points out, lay people view origins images so that they are comforted rather than challenged. So what is a caveman? He lives in caves, hunts wild beasts, wields stone tools, and masters nature, right? However, according to Moser, these artistic motifs predate origin's imagery, and they are borrowed from a succession of classical, biblical, medieval, and subsequent artistic genres (Moser 1998, p 17). Yet this conditioned imagination is part of the universal visual lexicon almost all visitors call upon, including our modern-day tribe of New York City cavemen.

Clearly, the visual images produced by museums communicate ideas far beyond the control of the original scientific or artistic intent, which can be seen, for example, in their ability to project ideas that have not been articulated in the associated text or labels (or by the curator or exhibition's designers, as Tattersall explains later in this article). Furthermore, as Gifford-Gonzalez has noted, "For most viewers, realism [the artistic technique used in dioramas] is read as objective truth" (Gifford-Gonzalez 1993, p 28). Many scholars of scientific imagery have considered the persuasive effects of artistic "realism," a common artistic method. As Molyneaux states, "the use of naturalistic imagery implies a direct relationship between the representation and the world, transparent and without interpretive obstacles." The ideas represented claim truth to nature (Molyneaux 1997, p 2). As Gifford-Gonzalez has noted, "Reconstructions highlight, in almost surrealist form, the paradoxical mediation of fact and fiction" (GiffordGonzalez 1993, p 28). So what do we do about all of this?

\section{Part II: The Museum Educator's Encounter}

Of course, educators can't always intervene in visitors' perceptions of, and projections onto, the AMNH Hall of Human Origins dioramas. However, I have tried my hand at a couple of interventionist strategies - one through an open question-and-answer forum with visitors and another through workshops about the construction of dioramas themselves.

\section{Hall of Human Origins Sackler Educational Laboratory}

At AMNH, evolutionary educational work currently happens in the 2007 Spitzer Hall of Human Origins, curated by Ian Tattersall and Rob Desalle. The new exhibition has several advantages for educators, including a circular arrangement of the exhibition's hominid dioramas, which subverts the linear progress narrative interpreted by many visitors to the previous hall, and a display showing the stepby-step process of hominid model reconstruction by the AMNH's own Gary Sawyer, who built many of the models for display in the dioramas. The exhibition also includes the Sackler Educational Laboratory for Comparative Genomics and Human Origins (see Fig. 2), which is a unique and significant educational resource. It is a high-tech genetics and hominid morphology teaching lab and educational forum, allowing weekend visitors to spend time learning from an evolutionary scientist. (While I developed the lab during the exhibition's opening in 2007 and continue to run occasional workshops in the lab and hall, the current manager of the lab is Dr. Samara Rubinstein, a physical anthropologist and evolutionary geneticist).

From the outset, the weekend drop-in activity for museum visitors to the Sackler Lab was very successful. What visitors appreciated most was the chance to go "behind the scenes" into a laboratory and work with a museum scientist. Despite their unfailing disappointment that the skull casts they were holding and measuring were reproductions rather than real, visitors appreciated being able to do a hands-on, interactive activity. I often tried to reinforce to them the value of holding these quality casts in their hands and the value of being able to observe and measure these rare fossil specimens. They really seemed to come around to the value of this, evidenced by the fact that our most popular specimens-Lucy and the la Chapelle Neanderthal, of course - barely held up to the number of hands in demand for them. The lab has to regularly remove layers of fingerprints or repair the odd zygomatic arch-a positive sign, I think. Overall, the Lab is an opportunity for visitors to see human evolution as an accessible science rather than an esoteric one, and one not mysteriously hidden on the other side of the Museum walls. And situated as it is at the end of the Hall of Human Origins, it also offers visitors a unique museum opportunity to engage in a

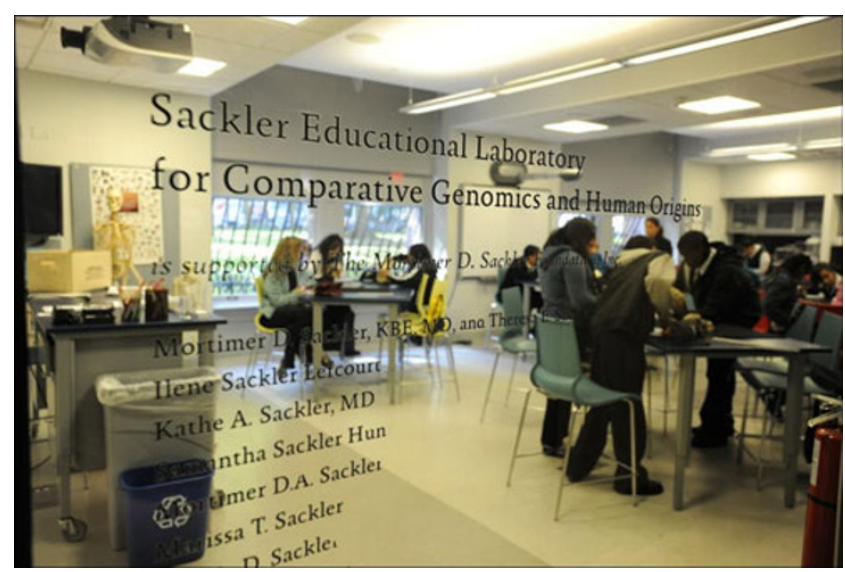

Fig. 2 The Sackler Educational Laboratory within the Hall of Human Origins. Credit: American Museum of Natural History 
hands-on, interactive laboratory experience with a scientist within the exhibition.

For many of the early Hall of Human Origins lab weekends, I experimented with how to run the sessions in order to develop a system for best utilizing the space. One of the most interesting challenges was reassuring surprisingly distressed visitors during the measurement activities that not every fossil cast has an upper canine or that sometimes it is hard to measure the size of the brow ridges with our rather crude calipers. I also emphasized that the pleasure and pain of doing paleontological work is that fossil data can be rather hard to quantify, and fossils do not fall into easy categories (like the seemingly straightforward quantitative data that genetic base changes seem to suggest).

Increasingly, I came to develop the lab into a space where visitors could ask me any questions they have about the exhibition in particular or human evolution at large. Without a doubt, this was the most successful and rewarding new aspect of the open workshops for me. When visitors came into the lab, I offered them the option of doing two quantitative activities but I also mentioned something like, "And here's your chance to ask any burning questions you have about human evolution. I'm here to do my best to answer any and all questions you have, big or small." I would stoke the fire by asking them about everything from their favorite films, commercials, and books about human evolution. This-fortunately or unfortunately - is a much more effective conversation starter than asking them what they have learned from the label copy on the mitochondrial clock. However, once visitors were comfortable talking about Land of the Lost or 2001: A Space Odyssey, I made it my mission to make it back to talking about the hard science, the label copy. I rely, then, on the old bait and switch, baiting them with popular culture before switching to hard science, something I learned from my interviewing years. Visitors seem to love this opportunity to chat informally about human evolution, even if it takes them a few minutes to warm up. They ask a colorful array of questions. I have often found myself discussing whether or not race is real, whether or not Neanderthals and modern humans made love or war, the origins of art, language and culture, why the missing link is still missing, whether or not we are still evolving, and whether the cross-like sutures on top of the human skull are an imprint of Christianity. I have been asked (by a boy looking scornfully at his younger brother) whether babies were "monkeys" because they lack bipedality, and (it being the aughts) I have even been asked about the taxonomic status of George W. Bush. There were a number of other engaging topics, such as whether or not we can get genetic material from early hominids and, quite thankfully, what kinds of evidence the dioramas are based on. After these sessions, visitors were usually wholeheartedly thankful for the experience. On some occasions, I found it hard to get visitors to leave - one young couple saying this is the seminar they wished they had in college. Interestingly, visitors were sometimes willing to spend hours in the lab even though a visitor study conducted in the museum found that visitors were spending only 20 minutes on average in the expansive Hall of Human Origins.

Overall, the experience of teaching in the lab - and now designing weekend programs with Dr. Rubinstein - has been extremely fulfilling. And as I continue to give workshops and tours of the Hall of Human Origins, I continue to learn from visitors as they challenge me with the most unexpected questions. The challenge is a good one, and one that keeps me, and other museum scientists, on our feet-and thus, perhaps, evolving.

\section{The Art and Science of Neanderthal Dioramas}

I have developed another rewarding workshop in the Hall of Human Origins that I refer to as "The Art and Science of Dioramas" (see Fig. 3). A direct response to my academic research, it has become a staple of my museum educational repertoire, something that can be used to engage - and I hope, inform-visitors of all ages, including elementary students, college students, graduate students, and teachers. The "Art and Science" workshops typically center around the much beloved Neanderthals, taking advantage of the research I gathered on their canonical image as caveman. I open the workshop with questions like: "What comes to mind when you think of a Neanderthal? What did Neanderthals actually look like? What did they do? Where have you seen them before? What images come to mind?" Then most importantly, I ask, "How do we know what we know about Neanderthals?," encouraging participants to develop critical lenses for looking at visual evolution displays.

I also point out that typically at the AMNH, we think of dioramas as a recreation of a natural setting and a rendering of a specific moment in time. But in human evolution exhibitions, these are merely artistic tableaux, and it's

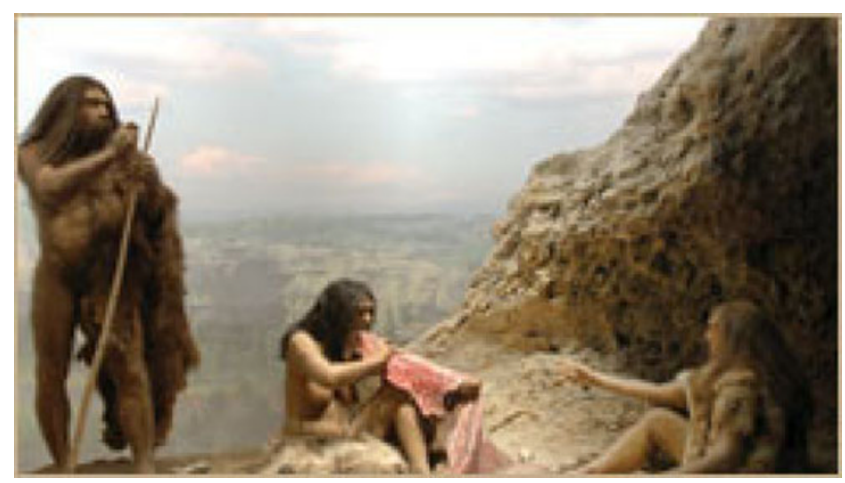

Fig. 3 Neanderthal reconstructions in the AMNH Hall of Human Origins. Credit: American Museum of Natural History 
important to understand them as such. (In fact, curator Tattersall bristles at the word diorama in relation to the Hall of Human Origins tableaux but I often use "diorama" with visitors to begin with language in which they're comfortable.) This encourages visitors to think critically about human evolution, to tease apart the science from the science fictions embedded in images - to divorce the animals they see in the Akeley Hall of African Animals from the animals depicted in the Hall of Human Origins (as when, during my academic research, some children would ask, "Why did they put those humans in there?," referring to a Hall of Human Origins diorama).

For the first half of the "Art and Science" workshop, I discuss the process of building reconstructions and point out how AMNH scientists recreate anatomy in front of our "Reconstructing Anatomy" display, showing the extraordinary work of Gary Sawyer. I then move on to discuss the creation of reconstructions of whole hominid scenes and lifestyles in front of the Neanderthal display - slowly moving from hard science (the anatomy, musculature) to the more speculative (such things as the facial expressions and facial hair).

The "Reconstructing Anatomy" display features a video of Gary Sawyer at work reconstructing a model. The exhibit says that "Drawing upon modern skulls and faces, facial reconstruction experts sculpt highly detailed models of long-dead hominids using fossil skulls as fragments, since the smallest variations in bone shape or texture can suggest particular facial features. By paying attention to tiny details, those experts truly bring the dead to life." Visitors can witness, step-by-step, that in the trajectory from fossil to flesh to face, it begins grounded in hard science (the skeletal anatomy, the musculature, even the cheekbones and nasal width). Then it increasingly comes to life with more imaginative, artistic elements (the expression, the wrinkles, the hairstyle). The viewer, then, sees the "picture" in a new light: as an amalgamation of informed and deliberate choices.

I also share with visitors Ian Tattersall's own words regarding the pleasures and pains of reconstructing the past. When the previous Hall of Human Biology and Evolution opened in 1993 (which included many of the same dioramas, including the Neanderthal diorama), Tattersall wrote in Scientific American:

Our arbitrary decisions were still only beginning. Once I would have laughed if anyone had predicted that I would spend weeks agonizing over Neanderthal eyebrows. Did they even have eyebrows? (Our closest living nonhuman relatives, the chimpanzees, do not.) If Neanderthals did have eyebrows, where were they on those bulbous brow ridges? Similarly, how long would untended Neanderthal beards have grown? How much body hair did the men and women have? What was its color and texture? What was the skin color? All these details offered endless scope for quibbling.

Students and visitors are always very intrigued when I share this information, if not disturbed. If scientists can't tell us how bushy Neanderthal eyebrows are, then who can? This becomes a great platform for questioning visitors why their own interests lie in the bushiness of Neanderthal eyebrows rather than the infinitely more interesting occipital bun or barreled rib cage of Neanderthal anatomy. And it's a great platform for having them move away from their predisposition towards easy adaptationist explanations for characteristics.

From reconstructing anatomy, we move to the Neanderthal diorama to consider the reconstruction of the Neanderthal lifestyle, which includes considering diets, language, fur coats, gender roles, and inevitably, hairstyles. (I blame this on those Geico commercials and endless film representations of Neanderthal men with the shaggy yet well-kempt beards.) Here, I try to point out that models and motifs - the whole environmental scene - are not one and the same; we need to scientifically dissect the evidence behind each in their own right.

As someone that enjoys the history of physical anthropology and believes it contextualizes our present understandings in important ways, I always incorporate a historical perspective into my Neanderthal workshops. I usually begin by discussing how representations of Neanderthals are linked to visual traditions dating to the nineteenth century and that most popular images tend to lag doggedly behind current science. I always point out that there has been an enduring interest in Neanderthals since the first was found in the Neander Valley of Germany in 1856 (aside from the Gibraltor fossil found in 1848 that didn't come to public attention until much later). I also mention that the first Neanderthal created quite a stir (this occurred after Busk translated the German article into English in 1861, and after Darwin's publication of The Origin in 1859). Some people imagined it to be part human, part animal. Others imagined it to be a monstrous or grotesquely deformed human. Still others imagined it to be a very distant ancestor. While encouraging this critical exercise- - "How would you make sense of a fossil for which you have no context to understand it?"-I remind them that 150 years later, people still imagine and recreate the Neanderthal lifestyle in different ways. (I also remind them that this is not unlike relatively recent conversations around challenging, intriguing new finds, such as attempts to understand the taxonomic place of Flores, aka "the Hobbit" science meets pop culture again, which Tom Gundling has addressed in his work.)

In this workshop, one useful exercise is to point out several historical conventions for representing Neanderthals. In particular, there have been two primary ways of thinking about Neanderthals - as big, hairy, brutes and as good-natured 
guys next door (Moser 1992). Where do these ideas come from? Do they come from evidence? The idea of Neanderthals as brutes comes from a misinterpretation of a pathological Neanderthal fossil in 1909 by Marcelin Boule, who actually used his reconstruction to prove that Neanderthals were not on the human lineage. This was followed by Sir Arthur Keith in 1912, who used an illustration to argue that his Neanderthals were rather human-like, supporting his notion that they were on the human lineage. What this strategy attempts to convey to visitors is that images do not only respond to scientific arguments, they produce scientific opinion. Ultimately, the aim is to make museum visitors more savvy about visual images and the powerful circulation of information about human evolution within museums and the larger public sphere.

Most importantly, at the Hall of Human Origins Neanderthal diorama, I ask students to tell me which aspects of the representation are based on evidence and which are inference. Visitors of all ages usually respond enthusiastically and quite accurately once they become engaged. In the end, I make sure they take home certain knowledge, such as that an examination of the fossils can tell the ages, sex, and medical condition of the individuals, or that the wear pattern on the teeth can tell what the individuals ate and whether they were using their front teeth to hold animal skins. Investigations can also inform scientists what tools the hominids used and whether they were hunting; and they can tell from other faunal remains what they were hunting or what was hunting them, and scientists can tell from fossilized pollen what vegetation was around. On the other hand, we must make inferences about such characteristics as hair color and texture, skin color, and facial expressions, and I emphasize to students that they have to be wary of considering these visual images as objective, scientific truths.

In the end, I challenge participants to take a set of evidence-for example, two dimorphic, gender-different, Neanderthal fossil skeletons, one with arthritis, as well as a set of handaxes and a burial site with ochre pigment on a hollowed-out bear femur - and recreate their own scene. This challenges visitors to come up with and evaluate alternative scenarios based on the evidence, as well as to exercise their senses of creativity and artistry. My favorite scenarios (based on varying sets of evidence) was the diorama of a whole family of Neanderthals sleeping or the family of Neanderthals vomiting after a binge on some rancid meat (leaving one unfortunate family member dead). However, I also think it would be comical to see a group of Neanderthals running bare-chested and barefooted across the Brooklyn Bridge.

\section{Conclusion}

It has become clear to me that few human evolution exhibitions stand alone, and the images visitors viewed in one museum experience stand consciously and subconsciously beside other images they have seen throughout time and across space. As one Kenyan interviewee shrewdly commented to me when questioned as to one display's meaning, "meanings are in people." This could not have been better stated. While museum visitors learn some new ideas from human origins exhibitions, they also bring some of themselves and some powerful preconceived images to bear upon what they see.

So what is the big picture (visual pun intended)? I think my overarching finding is that the public benefits from more spaces for informal dialogue between scientists and museum visitors around the topic of human evolution. These forums go far in challenging preconceptions and having visitors think critically about the human evolutionary information they encounter at the museum, in their textbooks, and the larger cultural matrix of popular media. The cultural information visitors bring with them into the museum should not leave those of us in museums with a defeatist attitude. It does not lessen the responsibility of the museum to intervene in the wider culture; in fact, it places a greater burden on museums to relay more challenging and conscientious spaces for visitors to learn. Is it "so easy a caveman can do it?" I would think not. But equipped with our academic training as well as the latest goings on in popular evolutionary science news and culture, I think those of us responsible for evolutionary education are up for the challenge.

\section{References}

Gifford-Gonzalez D. You can hide but you can't run: Representations of women's work in illustrations of paleolithic life. Vis Anthropol Rev. 1993;9:23-41.

Molyneaux BL. The cultural life of images. In: Molyneaux BL, editor. The cultural life of images, visual representation in archaeology. London: Routledge; 1997. p. 1-10.

Moser S. The visual language of archaeology: a case study of the Neanderthals. Antiquity. 1992;66:831-44.

Moser S. Science and social values: presenting archaeological findings in museum displays. In: Smith L, Clarke A, editors. Issues in management archaeology. St. Lucia, QLD: Tempus Press; 1996a. p. 32-42.

Moser S. Visual representation in archaeology: depicting the missing link in human origins. In: Picturing Knowledge. 1996b. p. 184214. See Baigrie 1996.

Moser S. Ancestral images: the iconography of human origins. Ithaca: Cornell University Press; 1998.

Moser S, Gamble C. Revolutionary images: the iconic vocabulary for representing human antiquity. In: The Cultural Life of Images. 1997. p. 184-212. See Molyneaux 1997.

Scott M. Rethinking evolution in the museum: envisioning African origins. London: Routledge; 2007.

Trinkaus E, Shipman P. Neandertals: images of ourselves. Evol Anthropol. 1993;1(6):194-201. 